\title{
A complementary analysis of the porous structure of biochars obtained from biomass
}

\author{
Mirosław Kwiatkowski ${ }^{1}$ (1) $\cdot$ Dimitrios Kalderis $^{2}$
}

Received: 27 June 2019 / Revised: 31 August 2019 / Accepted: 3 October 2019 / Published online: 21 October 2019

(c) The Author(s) 2019

\begin{abstract}
This paper presents the results of the analysis of the porous structure of biochars produced from biomass, namely eucalyptus, wood chips, pruning waste and rice husk. The structural analysis was carried out using the BET, the t-plot, the NLDFT and the LBET methods, which yielded not only complementary information on the adsorptive properties of obtained biochars from these materials, but also information on the usefulness of the structural analysis methods in question for the research into an effect of the technology of carbonaceous adsorbent preparation.
\end{abstract}

Keywords Biochars $\cdot$ Pyrolysis $\cdot$ Adsorption $\cdot$ Porous structure $\cdot$ Numerical methods

\section{Introduction}

Carbonaceous adsorbents and the adsorption processes taking place on their surface have been the object of widespread research and application in a number of industrial processes, technologies, and areas of daily life [1-3]. In particular, these materials are used to rid the air of substances that are harmful to human health, including for protection from poisonous substances and for environmental protection in the processes of removing harmful substances from waste gases [4]. However, interest in cheap carbonaceous adsorbents such as biochar has been increasing in recent years [5-9]. Biochars is an adsorbent obtained after the pyrolysis of an organic feedstock [5-9].

Pyrolysis consists in the heating of raw materials either without the access of air or in inert gas atmosphere [10, 11]. At an early stage of pyrolysis, i.e. at about $300-350{ }^{\circ} \mathrm{C}$, the less durable links in the polymeric network break up and free macromolecules are formed. At the same time, substantial amounts of volatile components, namely water,

Mirosław Kwiatkowski

kwiatkow@agh.edu.pl

1 Faculty of Energy and Fuels, AGH University of Science and Technology, al. A. Mickiewicza 30, 30-059 Krakow, Poland

2 Department of Environmental and Natural Resources Engineering, Technological and Educational Institute of Crete, Crete, 73100 Chania, Greece carbon dioxide, methanol and methane, are discharged, and the atoms of carbon are regrouped into a more stable form. Cross-links between the macromolecules are also generated, and the stiff, network-like carbonaceous structure that develops in the process reflects the development of porosity of the material. When pyrolysis temperature exceeds $500{ }^{\circ} \mathrm{C}$, the structure becomes increasingly carbonised and aromatised as a result of the elimination of the atoms of hydrogen and oxygen [10-12].

The properties of the pyrolysis product are determined by factors, such as the end temperature of pyrolysis, process time, the rate of temperature rise, and process atmosphere [10-14]. The end temperature of pyrolysis is one of the most important parameters of the process, since a substantial amount of energy has to be delivered in order to break up the less durable links, distil the volatile products of thermal decomposition of the raw material, and organise a dense carbonaceous substance.

The scale of structural organisation of the pyrolysis product is also determined by the kept time at the end temperature of pyrolysis. When the end temperature of pyrolysis is lower than the temperature at which the basic reactions of thermal decomposition relevant for the given raw material are completed, further, slow decomposition of the carbonaceous substance continues with time [10-14]. The material produced in such conditions shows greater reactivity compared with the product in which the processes of organising the chemical composition of carbonaceous substance and forming carbon crystallites were brought to an end. 
On the other hand, when the end temperature of pyrolysis is higher than the temperature at which the crucial processes of thermal decomposition of carbon are concluded and the porous structure of the pyrolysis product is ultimately formed, the internal structure is further organised as the process is extended in time. However, the volume of the smallest pores decreases as pyrolysis is protracted, and the longer the time of keeping at the end temperature, the lower the reactivity of that biochar [10-14].

Another important parameter of pyrolysis is the rate at which the end temperature is reached [10-14]. A fast temperature rise causes an overlap between the particular stages of the thermal decomposition of carbon and the secondary mutual reactions of the products of pyrolysis, impeding the control of the formation of a porous structure in the biochar. Also, a rapid rise in temperature makes it significantly difficult to organise the chemical composition of the carbonaceous substance, which is due to the fact that the said processes require relevantly long time. When a fast heating rate is applied, the pyrolised material generates large amounts of volatile components over a relatively short time, which usually results in the development of pores having larger volumes than those produced by way of heating at a slower pace. The reactivity of the biochar produced at a fast heating rate is higher than in those produced with a slow increase in temperature.

Process atmosphere has a significant impact on the pyrolysis process as well as the mechanisms of secondary mutual reactions between the products and the reactions between those products and solid biochar. When the gases and vapours generated during pyrolysis are quickly removed by means of a stream of inert gas, the process is less effective, while the reactivity of the biochar increases. The course of pyrolysis and the properties of the produced biochar are also largely influenced by the chemical structure of the raw material.

Pyrolysis results in the development of a carbonaceous structure that is a gathering of crystallites of graphite-like form bound into a spatial polymer by means of aliphatic links. The gaps between the neighbouring crystallites form the primary porous structure of carbon, but the pores of carbonised granules are often filled with tar decomposition products and blocked by amorphous carbon. Consequently, the parameters of the primary porous structure developed by way of pyrolysis are insufficient for the majority of adsorption processes.

\section{Materials and methods}

The paper presents the results of analyses concerning the adsorptive properties and porous structure of biochars obtained by way of slow pyrolysis from waste materials, namely eucalyptus, wood chips, pruning waste, and rice husk. Biochars were prepared by slow pyrolysis with samples being pyrolysed by increasing the temperature to, respectively, $600{ }^{\circ} \mathrm{C}, 620^{\circ} \mathrm{C}, 500{ }^{\circ} \mathrm{C}$, and $500{ }^{\circ} \mathrm{C}$. The final temperature for all samples was maintained for $2 \mathrm{~h}$. The structure of the said porous materials was analysed on the basis of the isotherms of nitrogen adsorption at $77 \mathrm{~K}$ using the BET [15], the t-plot [16, 17], the DFT [18-21] and the LBET methods [22-26].

A less popular of the methods incorporated for the purposes of the analyses in question, the LBET method has been described in detail in previous works [22-26]; it is based on the original analytical LBET class models of adsorption on heterogeneous surfaces and the numerical procedure of fast multivariant identification of adsorption systems. The LBET class models involve six parameters, i.e. $V_{h A}$ - the volume of the first adsorbed layer $\left(\mathrm{cm}^{3} / \mathrm{g}\right), Q_{A} / R T$ - the dimensionless energy parameter for the first layer, $B_{C}$-the dimensionless energy parameter for the higher layers, $\alpha$-the geometrical parameter of the porous structure determining the height of the adsorbate molecules clusters, $\beta$-the average number of sites provided by $(n-1)$ th layer for the $n$th layer, $n=2, k$, averaged over all adsorbate molecules clusters $(\beta=1$ for narrow pores, $\beta>1$ for wider ones), and $Z_{A}$-effective contact correction factor, which can be adjusted by fitting of the LBET formula to the adsorption isotherm, with a chosen variant of the surface energy distribution function [22-26].

\section{Results and discussion}

The porous structure of biochars produced from waste raw materials by slow pyrolysis was analysed on the basis of the isotherms of nitrogen adsorption at $77 \mathrm{~K}$; the activated carbons had been obtained from eucalyptus (EBC), wood chips (WBC), pruning waste (PBC), and rice husk (RHBC), using the BET [15], the t-plot [16, 17], the DFT [18-21] and the LBET methods [22-26]. The results of these analyses are compiled in Table 1. Also, the analysed nitrogen adsorption isotherms and diagrams of adsorption energy distribution on the first adsorbed layer are compiled in Fig. 1.

Drawing on the results of analyses concerning the isotherms of nitrogen adsorption at the temperature of $77 \mathrm{~K}$ that are compiled in Table 1, it can be concluded that the biochar obtained from eucalyptus and marked EBC is characterised by the highest values of the specific surface area parameter among the biochars subject to the analysis; however, it must be pointed out that the said values is still relatively low, namely $S_{B E T}=334.5 \mathrm{~m}^{2} / \mathrm{g}$ and $S_{t-p l o t}=326.2 \mathrm{~m}^{2} / \mathrm{g}$. The value of total volume $V_{T}$ obtained for the analysed sample is also average, yet it can be observed on the basis of the parameter $V_{\text {micro ( } t \text {-plot) }}$ denoting the volume of micropores determined by means of the t-plot method that the volume 
Table 1 Results of the analysis of the porous structure of biochars

\begin{tabular}{lcccc}
\hline Structure parameters & \multicolumn{4}{l}{ The biochars } \\
\cline { 2 - 5 } & EBC & WBC & PBC & RHBC \\
\hline$S_{B E T}\left(\mathrm{~m}^{2} / \mathrm{g}\right)$ & 334.5 & 332.1 & 174.5 & 92.6 \\
$S_{\text {t-plot }}\left(\mathrm{m}^{2} / \mathrm{g}\right)$ & 326.2 & 305.9 & 165.1 & 66.9 \\
$V_{T}\left(\mathrm{~cm}^{3} / \mathrm{g}\right)$ & 0.161 & 0.176 & 0.099 & 0.076 \\
$V_{\text {micro }(t-p l o t)}\left(\mathrm{cm}^{3} / \mathrm{g}\right)$ & 0.148 & 0.140 & 0.0767 & 0.0316 \\
$w(\mathrm{~nm})$ & 1.94 & 1.85 & 1.09 & 2.20 \\
$V_{\text {micro }(D F T)}\left(\mathrm{cm}^{3} / \mathrm{g}\right)$ & 0.148 & 0.128 & 0.065 & 0.033 \\
$V_{T(D F T)}\left(\mathrm{cm}^{3} / \mathrm{g}\right)$ & 0.153 & 0.153 & 0.085 & 0.069 \\
$\mathrm{LBET} \mathrm{No.}$ & 4 & 7 & 15 & 30 \\
$V_{\text {hA }}$ & 0.139 & 0.138 & 0.074 & 0.041 \\
$Q_{A} / R T$ & -10.60 & -8.21 & -10.24 & -8.37 \\
$B_{C}$ & 6.91 & 6.91 & 6.91 & 6.91 \\
$Z_{A}$ & 0.478 & 0.416 & 0.469 & 0.420 \\
$h$ & 3 & 5 & 9 & 9 \\
$\alpha$ & 0.36 & 0.24 & 0.18 & 0.47 \\
$\beta$ & 1.02 & 2.65 & 3.01 & 3.36 \\
$\sigma_{e}$ & 0.02 & 0.04 & 0.066 & 0.019 \\
$w_{\text {id }}$ & 0.64 & 0.41 & 0.43 & 0.57 \\
\hline
\end{tabular}

of micropores is prevalent in the total volume. That conclusion is further confirmed by the results obtained using the DFT method, namely the parameter values $w=1.94 \mathrm{~nm}$, $V_{\text {micro }(D F T)}=0.148 \mathrm{~cm}^{3} / \mathrm{g}$ and $V_{T(D F T)}=0.153 \mathrm{~cm}^{3} / \mathrm{g}$, which point to the average pore size that fluctuates around the largest pore range and to the prevalence of micropores in the total pore volume of the biochar sample in question.

Interesting results came with the analysis of the isotherm of nitrogen adsorption on the biochar EBC carried out using the LBET method; more specifically, the results in question show that the surface of the mentioned sample EBC is heterogeneous $(h=3)$, while the value of the parameter of the first adsorbed layer volume $V_{h A}$ implies the occurrence in the analysed material of favourable conditions for the adsorption of adsorbate particles directly on the surface of the adsorbent. The limitations to nitrogen particle cluster growth are due to competitive adsorption, i.e. the occupation of the neighbouring adsorption sites by nitrogen particles belonging to different clusters.

The values of the energy parameters, i.e. the energy of adsorption on the adsorbent surface $Q_{A} / R T$ and the energy of adsorption on the higher layers $B_{C}$, also testify to the soundness of the conclusions arrived at before. The shape of adsorption energy distribution on the surface of the analysed adsorbent points to the prevalence of the adsorption sites that display a very narrow range of energy values and the to the occurrence of sites with a very broad range of adsorption energy, which, given the value of the effective contact parameter $Z_{A}$, denotes the prevalence in the analysed material of the adsorption sites that are comparable
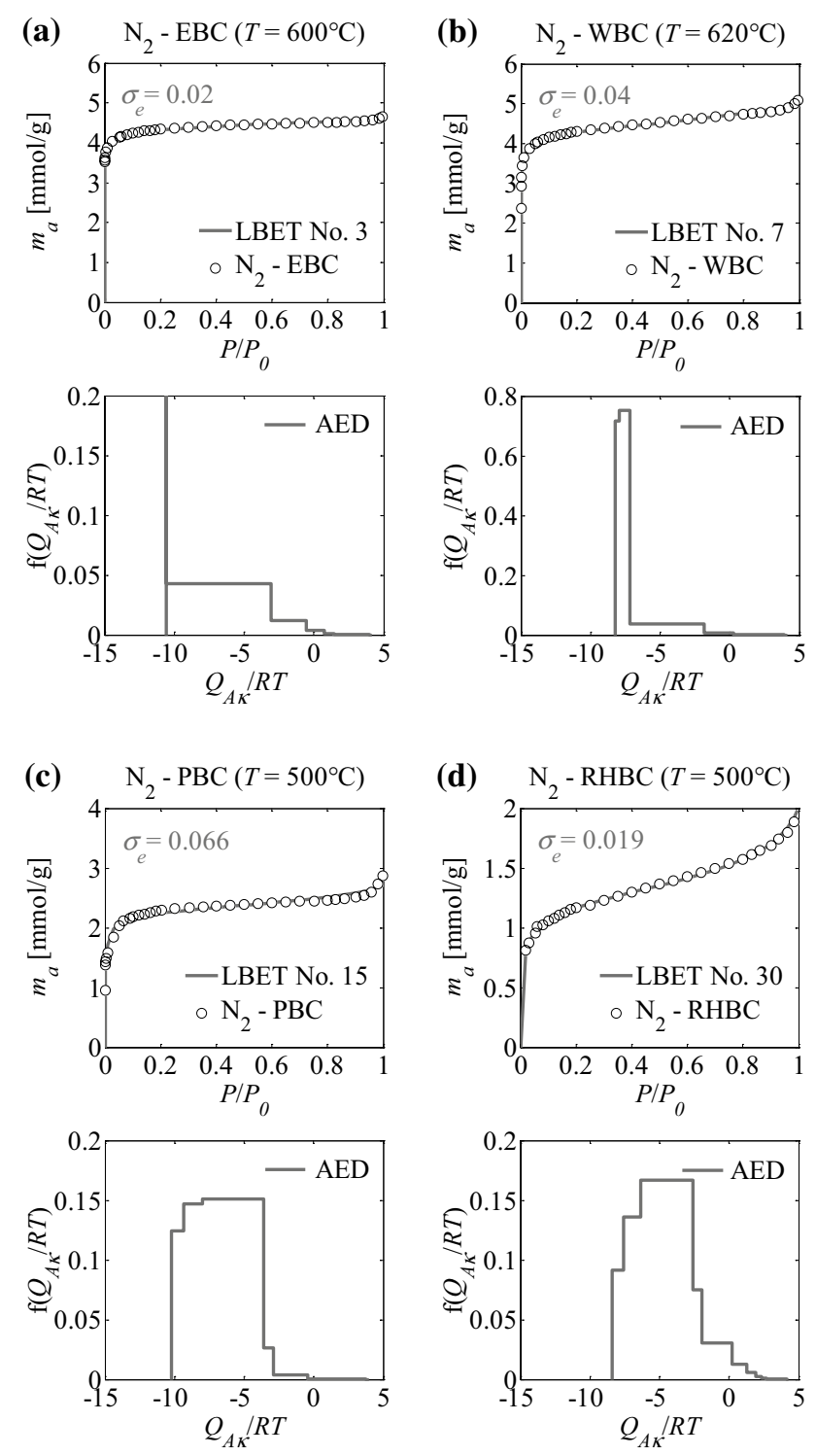

Fig. 1 Results of the fast multivariant identification for the obtained nitrogen adsorption isotherms and the diagrams of adsorption energy distribution on the first adsorbed layer for: a eucalyptus (EBC), b wood chips (WBC), c pruning waste (PBC) and rice husk (RHBC) by way of slow pyrolysis

in size with the adsorbed particles of nitrogen. On the other hand, the values of the geometrical parameters $\alpha=$ 0.36 and $\beta=1.02$ evidence that low and unbranched clusters of nitrogen particles are formed in the micropores of the analysed material. The fitting error dispersion value $\sigma_{e}$ and the identification indicator value $w_{i d}$ both testify to substantial reliability and validity of the results obtained using the LBET method. It is also interesting to note a very good correlation of results obtained with different methods, namely the BET, the t-plot, the DFT, and the LBET, which confirms the aptness of the assumptions made in these methods. 
Another analysed material was biochar produced from wood chips by way of slow pyrolysis and marked WBC. Based on the analyses of the isotherms of nitrogen adsorption on this adsorbent, a conclusion can be drawn that the material in question has adsorptive properties that are very similar to those of the biochar EBC analysed above. Still, it is important to note a higher share of the volume of mesopores in the total pore volume, and higher surface heterogeneity $(h=5)$. Moreover, the micropores of the biochar WBC contain low and branched clusters of nitrogen particles. The same as in the case described above, this adsorption system is also highly identifiable.

The subsequently analysed biochar sample, obtained from pruning waste and marked PAC, is characterised by evidently worse adsorption parameters compared with the formerly analysed biochar designated EBC and WBC. It is particularly important to note the relatively low value of the parameters that define the specific surface area, namely $S_{B E T}$ and $S_{t-p l o t}$, and the low values of the parameters $V_{T}$ and $V_{\text {micro (t-plot) }}$, or the total pore volume and the volume of micropores, respectively. Notably, the average pore size - pore diameter-is the smallest compared with those in other analysed samples and testifies to a prevalence of micropores in the porous structure of the biochar PAC subject to the analysis. The results obtained using the DFT method, i.e. for the parameters $V_{\text {micro (DFT) }}$ and $V_{T(D F T)}$, are correlated with the values discussed above. Drawing on the analysis carried out using the LBET method, it can be observed that - contrary to the biochars analysed beforethe limitations to nitrogen particle cluster growth result from the geometrical limitations of pores as evidenced by the number of the best-fitted LBET class model. Also, the surface of the biochar PAC is highly heterogeneous.

The nitrogen particle clusters formed in the pores of the analysed material are low and branched, which is reflected in the value of the energy parameters $\alpha$ and $\beta$. The shape of the diagram of how adsorption energy is distributed on the surface of the biochar PBC evidences the occurrence of a broad energy spectrum of the primary adsorption sites. In parallel to the samples analysed before, it is also noteworthy that the theoretical isotherms are very well fitted with the empirical data, and that the system is highly identifiable, which testifies to a considerable reliability and validity of the results.

The last one to undergo the analysis was a sample of the biochar obtained from rice husk and marked RHBC. Of all the analysed samples, the biochar RHBC is characterised by both the smallest specific surface areas determined using the BET and the t-plot methods compared with the remaining samples and the smallest pore volumes, i.e. total pore volume and the volume of micropores. It is interesting to note a smaller proportion of micropores to the total pore volume, which testifies to a higher proportion of mesopores in the structure of the analysed material marked RHBC. Such conclusions are also confirmed by the average pore size in the analysed material as determined using the DFT method. An analysis by means of the LBET method has revealed that the volume of the first adsorbed layer is also the smallest compared to all the biochars subject to the analysis. The biochar RHBC is also characterised by very high surface heterogeneity as evidenced by the value of the $h$ parameter. Most interestingly, however, the nitrogen particle clusters formed in the micropores of this material are average in height and significantly branched, being the largest ones compared with the remaining biochar subject to the analysis.

The shape of the adsorption energy distribution on the surface of the biochar PBC points to the occurrence of a broad range of energy of primary adsorption sites, with a prevalence of the sites with an average adsorption energy value, which distinguishes this sample from the previously analysed one. With regard to all the biochars subject to the analysis, very low fitting error dispersion values and satisfactory identifiability indicator values were obtained, which is an unambiguous evidence that the results arrived at are valid and the analyses in question are reliable.

It is also interesting to note a correlation between the results produced using different methods, i.e. the BET, the t-plot, the DFT and the LBET. Still, as can be seen from the results of analyses compiled in Table 1 , the values of the specific surface parameter $S_{B E T}$ determined using the BET method are higher than those produced with the t-plot method. This confirms a repeated conclusion provided in the literature, namely that when applied in the context of microporous materials, the BET method may overestimate the surface area. The analyses described in this article point to the LBET method as a very useful tool for technologists dealing with the production of biochars; that method offers a much broader range of information compared with the remaining ones used in the research.

\section{Conclusions}

The aim of the research in question was to assess the adsorptive properties and porous structure of the biochars produced from biomass-originated waste material by way of slow pyrolysis. The research permits a conclusion that the best adsorptive properties and a moderate surface heterogeneity characterised the biochar EBC produced from eucalyptus. Very similar properties were shown for the biochar marked WBC and obtained from wood chips, although its surface was evidently more heterogeneous. The next biochar subject to the analysis, marked PBC and developed from pruning waste, had much worse adsorptive properties, i.e. smaller specific surface area, smaller pore volume, including the volume of micropores, and higher surface heterogeneity. Still, by far the worst adsorptive properties were those of the biochar signed RHAC and derived from rice husk. It must be borne in 
mind, however, that in spite of its poorest adsorptive properties, the latter adsorbent cannot be discredited as useless for industrial purposes and everyday use, since its raw material is commonly available and can be acquired at a very low cost. The same applies to the remaining biochar obtained from biomass-originated waster material, which pose a threat to the natural environment when left to lie idle, while a simple and cheap process of their conversion into relatively costeffective biochar renders them useful for different purposes, including in the realm of environmental protection.

Finally, the research pointed to a correlation between the results produced using different methods, i.e. the BET, the t-plot, the DFT and the LBET, testifying to the validity of the assumptions behind the tests and of the mathematical apparatus behind these methods.

Acknowledgements The work was financed from the Research Subvention from the Polish Ministry of Science and Higher Education for the AGH University of Science and Technology in Krakow No. 16.16.210.476.

Open Access This article is distributed under the terms of the Creative Commons Attribution 4.0 International License (http://creativeco mmons.org/licenses/by/4.0/), which permits unrestricted use, distribution, and reproduction in any medium, provided you give appropriate credit to the original author(s) and the source, provide a link to the Creative Commons license, and indicate if changes were made.

\section{References}

1. Ahmed MB, Zhou JL, Ngo HH, Guo W, Chen M (2016) Progress in the preparation and application of modified biochar for improved contaminant removal from water and wastewater. Bioresour Technol 214:836-851

2. Chiang Y-Ch, Juang R-Sh (2017) Surface modifications of carbonaceous materials for carbon dioxide adsorption: a review. $\mathrm{J}$ Taiwan Inst Chem Eng 71:214-234

3. Moura FCC, Rios RDF, Galvão BRL (2018) Emerging contaminants removal by granular activated carbon obtained from residual Macauba biomass. Environ Sci Pollut Res Int 25:26482-26492

4. Kalderis D, Koutoulakis D, Paraskeva P, Diamadopoulos E, Otal E, Olivares del Valle J, Fernandez-Pereira C (2008) Adsorption of polluting substances on activated carbon prepared from rice husk and sugarcane bagasse. Chem Eng J 144:42-50

5. Lehmann J, Joseph S (2009) Biochar for environmental management, science and technology. Earthscan, London

6. Gascó G, Paz-Ferreiro J, Méndez A (2012) Thermal analysis of soil amended with sewage sludge and biochar from sewage sludge pyrolysis. J Thermal Anal Calorim 108:769-775

7. Pellera F-M, Giannis A, Kalderis D, Anastasiadou K, Stegmann R, Wang J-Y, Gidarakos E (2012) Adsorption of $\mathrm{Cu}$ (II) ions from aqueous solutions on biochars prepared from agricultural byproducts. J Environ Manag 96:35-42

8. Méndez A, Gómez A, Paz-Ferreiro J, Gascó G (2012) Effects of sewage sludge biochar on plant metal availability after application to a Mediterranean soil. Chemosphere 89:1354-1359

9. Gascó G, Cely P, Paz-Ferreiro J, Plaza C, Méndez A (2016) Relation between biochar properties and effects on seed germination and plant development. Biol Agric Hortic 32(4):237-247

10. Sreńscek-Nazzal J, Kamińska W, Michalkiewicz B, Koren ZC (2013) Production, characterization and methane storage potential of $\mathrm{KOH}$-activated carbon from sugarcane molasses. Ind Crops Prod 47:153-159

11. Ahmed MB, Zhou JL, Ngo HH, Guo W (2016) Insight into biochar properties and its cost analysis. Biomass Bioenergy 84:76-86

12. Serafin J, Narkiewicz U, Morawski AW, Wróbel RJ, Michalkiewicz B (2017) Highly microporous activated carbons from biomass for $\mathrm{CO}_{2}$ capture and effective micropores at different conditions. J CO2 Util 18:73-79

13. Wu H, Chen R, Du H, Zhang J, Shi L, Qin Y, Yue L, Wang J (2018) Synthesis of activated carbon from peanut shell as dye adsorbents for wastewater treatment. Adsorpt Sci Technol 37:1-15

14. Larbia K, Benderdouche N, Reinert L, Lévéque JM, Delpeux-Ouldriane S, Benadjemia M, Bestani B, Duclaux L (2018) Tailored activated carbons prepared by phosphoric activation of apricot, date and loquat stones and their mixtures; relation between the pore size and the composition in biopolymer. Desalin Water Treat 120:217-227

15. Brunauer S, Emmett PH, Teller E (1938) Adsorption of gases in multimolecular layers. J Am Chem Soc 60:309-319

16. Lippens BC, de Boer JH (1965) Studies on pore systems in catalysts: V. The t method. J Catal 4:319-323

17. De Boer JH, Lippens BC, Linsen BG, Broeckhoff JCP, van den Heuvel A, Onsinga TV (1966) The t-curve of multimolecular $\mathrm{N}_{2}$-adsorption. J Colloid Interf Sci 21:405-414

18. Lastoskie C, Gubbins KE, Quirke N (1993) Pore size distribution analysis of microporous carbons: a density functional theory approach. J Phys Chem 97:4786-4796

19. Olivier JP, Conklin WB, Von Szombathely M (1994) Determination of pore size distribution from density functional theory: a comparison of nitrogen and argon results. Stud Surf Sci Catal 87:81-89

20. Olivier JP (1998) Improving the models used for calculating the size distribution of micropore volume of activated carbons from adsorption data. Carbon 10:1469-1472

21. Neimark AV, Ravikovitch PI, Vishnyakov A (2003) Bridging scales from molecular simulations to classical thermodynamics: density functional theory of capillary condensation in nanopores. J Phys Condens Matter 15:347-365

22. Kwiatkowski M (2007) Computer analysis of microporous structure by employing the LBET class models with various variants of the adsorption energy distribution in comparison to the classical equations. Langmuir 23:2569-2581

23. Kwiatkowski M, Policicchio A, Seredych M, Bandosz TJ (2016) Evaluation of $\mathrm{CO}_{2}$ interactions with S-doped nanoporous carbon and its composites with a reduced GO: effect of surface features on an apparent physical adsorption mechanism. Carbon 98:250-258

24. Kwiatkowski M, Fierro V, Celzard A (2017) Numerical studies of the effects of process conditions on the development of the porous structure of adsorbents prepared by chemical activation of lignin with alkali hydroxides. J Colloid Interface Sci 486:277-286

25. Kwiatkowski M, Broniek E (2017) An analysis of the porous structure of activated carbons obtained from hazelnut shells by various physical and chemical methods of activation. Colloids Surf A 529:443-453

26. Kwiatkowski M, Kalderis D, Diamadopoulos E (2017) Numerical analysis of the influence of the impregnation ratio on the microporous structure formation of activated carbons, prepared by chemical activation of waste biomass with phosphoric acid. J Phys Chem Solids 105:81-85

Publisher's Note Springer Nature remains neutral with regard to jurisdictional claims in published maps and institutional affiliations. 